\title{
SISTEM PROTEKSI TEGANGAN SENTUH PADA INSTALASI LISTRIK BERBASIS EARTH LEAGAGE CIRCUIT BREAKER (ELCB)
}

\author{
Syarifil Anwar ${ }^{1)}$ \\ ${ }^{1}$ Program Studi Teknik Listrik, Akademi Teknik Pembangunan Nasional Banjarbaru \\ Email: syarifilanwar@gmail.com
}

\begin{abstract}
An electrical installation is a series of electrical installation equipment that connects an conductor with the electrical equipment used (consumers). The protection factor (safety) is a consideration that must be considered in designing an electrical installation so that it can be used optimally, effectively, efficiently, safely, properly and correctly while ensuring fire safety, of course in accordance with the General Requirements for Electrical Installation (PUIL) 2011. Touch voltage, which means that if a live wire is touched or held on a cable that is stripped of its insulation, then we will be electrocuted. Therefore, in the installation of electrical installations, there must be additional safety besides the Miniature Circuit Breaker (MCB). The additional safeguards are the neutral point (ground) ground and the Earth Leakege Circuit Breaker (ELCB). Electrical installations that use Earth Leakege Circuit Breaker (ELCB) safety must install a neutral point (Ground) ground as a condition for the Earth Leakege Circuit Breaker (ELCB) to work properly and correctly, meaning that if there is a touch voltage we will not be electrocuted, because the MCB and The ELCB will be disconnected (Trip) simultaneously.
\end{abstract}

Keywords: Electrical Installation, Protection System, Earth Leakege Circuit Breaker

\section{PENDAHULUAN}

Perkembangan zaman yang semakin modern dan canggih menyebabkan peralatan listrik untuk perkantoran, Mall dan perumahan yang digunakan semakin modern, sehingga memerlukan energi listrik yang lebih banyak pula, hal ini tidak dapat kita hindari dan lambat laun kita akan mengikuti perkembangan zaman tersebut.

Banyak konsumen tegangan rendah menggunakan peralatan rumah tangga dan perkantoran serta pertokoan besar menggunakan motor listrik, motor pompa, UPS, AC, dispenser, kulkas dan elektronika lainnya yang menyebabkan penggunan tenaga listrik lebih besar.

Energi listrik yang kita gunakan saat ini berasal dari pembangkit tenaga listrik dan disalurkan ke Gardu Induk (Step Up) dimana tegangannya dinaikkan ke Tegangan tinggi (TT), kemudian disalurkan melalui sistem transmisi ke Gardu Induk (step down) dimana tegangannya diturunkan menjadi tegangan menengah (TM) selanjutnya energi listrik disalurkan ke gardu distribusi dimana tegangannya diturunkan lagi menjadi tegangan rendah (TR) yang digunakan oleh sistem distribusi sekunder untuk disalurkan ke komsumen (TR).

Instalasi listrik adalah suatu rangkaian peralatan instalasi listrik yang menghubungkan antara suatu penghantar dengan peralatan listrik yang digunakan (konsumen). Faktor Proteksi (Pengaman) merupakan suatu pertimbangan yang wajib diperhatikan dalam mendesain suatu pemasangan Instalasi Listrik agar dapat digunakan secara optimum, efektif, efisien, aman, baik dan benar sekaligus menjamin keamanan kebakaran yang sesuai dengan Persyaratan Umum Instalasi Listrik (PUIL) 2011 dan harus sesuai dengan Standar Nasional Indonesia (SNI) dan tentunya memperhatikan kerapian dan estetika.

Oleh karena itu dalam pemasangan instalasi rumah harus ada pengaman tambahan disamping adanya Miniature Circuit Breaker (MCB), Pengaman tambahan itu berupa Earth Leakege Circuit Breaker (ELCB) dan Pentanahan titik netral (Arde) gunanya untuk mengamankan konsumen dari sengatan listrik yang disebabkan terjadinya tegangan sentuh, artinya bila konsumen tersentuh kabel yang beraliran listrik 
$(+)$, maka konsumen tidak akan tersengat listrik dan ELCB MCB juga akan off (tidak beroperasi).

Instalasi listrik yang menggunakan pengaman Earth Leakege Circuit Breaker (ELCB) harus selalu dihubungkan dengan pentanahan titik netral (Arde) sebagai syarat agar Earth Leakege Circuit Breaker (ELCB) bekerja dengan baik dan benar, Artinya bila terjadi tegangan sentuh konsumen tidak akan tersengat listrik, karena MCB dan ELCB akan terputus (Trip) bersamaan.

Beberapa penelitian yang pernah dilakukan yang berhubungan dengan ELCB dan Tegangan sentuh adalah penelitian yang dilakukan oleh Nuril Fifana (2008), tentang ELCB yang dapat melindungi tegangan sentuh bagi manusia, namun tidak membahas tentang hubungan ELCB dengan pentanahan titik netral (Arde) sebagai syarat agar pengaman ELCB beroperasi secara baik (Aman). Sarunggalo Pandung (2008), dalam penelitiannya mengenai perancangan ELCB dengan kemampuan pengamanan sensitivitas $30 \mathrm{~mA}$, tetapi hanya membahas tentang sensitivitas kemampuan pengaman ELCB tidak membahas masalah hubungannya dengan pentanahan titik netral (Arde). Nugroho Rohmat (2009) penelitiannya hanya membahas masalah penyebab terjadinya Arus bocor atau tegangan sentuh oleh konsumen dan tidak membahas tentang pengaman ELCB dan Pentanhan titik Netral (Arde).

Instalasi listrik yang semakin panjang dan rumit, sehingga dapat menimbulkan gangguan tegangan kejut (tersengat Listrik) yang disebabkan hubung pendek (Short Circuit), beban lebih (Over Load), hubungan teganagn fasa dengan fasa dan juga hubungan antar fasa dengan tanah semuanya yang akan berakhir dengan terjadinya gangguan pemadaman aliran listrik (Break). Untuk mengatasi gangguan tersebut, Maka dipasang pengaman MCB. (Badan Standarisasi Nasional, 2012).

Permintaan pemasangan instalasi listrik yang terus meningkat, disisi lain peralatan yang digunakan juga harus tahu cara pemasangannya dan kapasitas dan kekuatan dari peralatan listrik yang dipengaruhi oleh beban yang digunakan serta peralatan listrik yang digunakan harus sesuai dengan kemampuan tenaga listrik yang diperlukan (Harten, P. van. 1978)

Instalasi listrik sangat diperlukan pada sebuah bangunan/rumah, namun perlu diperhatikan mengenai cara pemasangan dan peralatan yang digunakan harus sesuai syarat yang telah di tentukan secara optimal dan yang sesuai dengan peraturan yang telah tercantum dalam Peraturan Umum Instalasi Listrik (Tim penyusun PLN dan ESDM, 2000)

Namun dalam penelitian ini peneliti membahas secara keseluruhan yang dibahas oleh peneliti terdahulu baik membahas pengaman ELCB, membahas tegangan sentuh (arus Bocor) dan yang penting dan juga yang membedakan penelitian ini adalah membahas masalah pentanahan titik Netral (arde) sebagai syarat untuk agar ELCB dapat beroperasi secara aman dan baik

\section{METODE PENELITIAN.}

Penelitian dilakukan dengan menggunakan metode diskriptif dan metode kuantitatif berdasarkan pada:

a. Perpustakaan (library research). yaitu buku-buku yang terkait dengan judul penelitian

b. Survey secara langsung ke PT. Konsuil Banjarbaru, dengan cara wawancara secara langsung (field research)

\section{HASIL DAN PEMBAHASAN}

Energi listrik yang kita gunakan saat ini berasal dari pembangkit tenaga listrik dan disalurkan ke Gardu Induk (Step Up) dimana tegangannya dinaikkan ke Tegangan tinggi (TT), kemudian disalurkan melalui sistem transmisi ke Gardu Induk (step down) dimana tegangannya diturunkan menjadi tegangan menengah (TM) selanjutnya energi listrik disalurkan ke gardu distribusi dimana tegangannya diturunkan lagi menjadi tegangan rendah (TR) yang digunakan oleh sistem distribusi sekunder untuk disalurkan ke komsumen (TR). Instalasi listrik adalah suatu rangkaian peralatan instalasi listrik yang disatukan untuk menghubungkan antara penghantar listrik dengan peralatan listrik (konsumen)

Instalasi listrik adalah suatu rangkaian peralatan instalasi listrik yang menghubungkan antara suatu penghantar dengan peralatan listrik yang digunakan (konsumen). Faktor Proteksi (Pengaman) merupakan suatu pertimbangan yang wajib diperhatikan dalam mendesain suatu pemasangan Instalasi Listrik agar dapat digunakan secara optimum, efektif, efisien, aman, baik dan 
benar sekaligus menjamin keamanan kebakaran yang sesuai dengan Persyaratan Umum Instalasi Listrik (PUIL) 2011 dan harus sesuai dengan Standar Nasional Indonesia (SNI) dan tentunya memperhatikan kerapian dan estetika.

\section{instalasi listrik}

Berdasarkan pemakaian energi listrik dan tegangannya, instalasi listrik dapat dibedakan menjadi 2 (dua) jenis yaitu: Instalasi Penerangan dan instalasi daya/tenaga.

Pemasangan suatu sistem instalasi listrik harus memenuhi ketentuan yang tertuang dalam Persyaratan Umum Instalasi Listrik (PUIL) dan Peraturan lain seperti Undang-Undang Nomor 1 tahun 1970 tentang keselamatan kerja, Beserta Peraturan Pelaksanaannya, Undang-Undang Nomor 23 Tahun 1997 tentang Pengelolaan Lingkungan Hidup, Undang-Undang Nomor 15 tahun 2002 tentang Ketenagalistrikan, dan Pemasangan instalasi listrik harus memenuhi ketentuan PUIL 2011 dan peraturan yang terkait dalam dokumen seperti UU No 18 Tahun 1999 tentang jasa konstruksi, Peraturan Pemerintah No.51 Tahun 1995 tentang Usaha Penunjang Tenaga Listrik dan peraturan lainnya.

Dalam pemasangan sistem instalasi listrik harus diperhatikan tentang keselamatan manusia, makhluk hidup lain dan keamanan harta benda dari bahaya dan kerusakan yang bisa ditimbulkan oleh penggunaan energi listrik. Selain itu instalasi listrik harus dalam keadaan baik dan benar yang sesuai dengan PUIL tahun 2011 dan peraturan yang tertuang dalam SNI.

\section{Komponen-komponen instalasi listrik}

Dalam pemasangan instalasi Listrik diperlukan adanya perencanaan dan persiapan yaitu menyiapkan gambar, tempat lokasi dan komponen yang diperlukan. agar pemasangan instalasi listrik dapat berlangsung dengan lancar dan baik. Komponen-komponen utama dapat terlihat dalam Tabel 1.

\section{Kabel Tunggal/pejal (solid)}

Kabel Tunggal (solid) berisi satu logam tembaga (inti tunggal) yang mana bagian luarnya dilapisi dengan plastik pvc yang disebut dengan kabel pejal/Tunggal (solid) yaitu kabel dengan diameter bulat dengan berukuran sampai $10 \mathrm{~mm}^{2}$. Tidak dibuat lebih besar lagi dengan maksud untuk memudahkan dalam pengelolaan kabel maupun pemasangannya, untuk lebih jelasnya lihat pada gambar, dibawah ini.

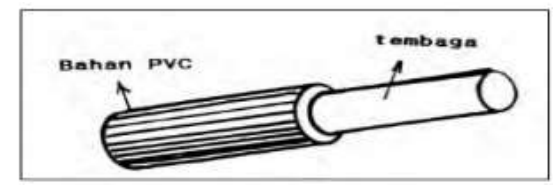

Gambar.1. Penghantar pejal (solid)

Tabel. 1. Komponen instalasi listrik

\begin{tabular}{ccc}
\hline No & Nama Komponen & Besaran \\
\hline 1 & Kabel NYA & $2.5 \mathrm{~mm}$ \\
2 & Box MCB & 2 Group \\
3 & MCB & $4 \mathrm{~A}$ \\
4 & ELCB/RCBO & $20 \mathrm{~A} / 30 \mathrm{ma}$ \\
5 & Tusuk kontak & - \\
6 & Kabel NYM & $3 \times 2.5 \mathrm{~mm}$ \\
7 & Pipa PVC & $5 / 8 ”$ \\
8 & ELBOW & - \\
9 & Kotak sambung & - \\
10 & Saklar Tunggal & - \\
11 & Stop Kontak & - \\
12 & Fitting Lampu & - \\
13 & Isolasi & - \\
14 & Klem & $17 ”$ \\
\hline
\end{tabular}

\section{Kabel Serabut/berlilit (stranded)}

Kabel ini terbuat dari beberapa logam tembaga (berinti banyak) dengan diameter kecil dan dipilin menjadi satu kesatuan yang mana bagian luarnya dilapisi dengan plastik pvc yang disebut dengan kabel serabut/berlilit (stranded) disebut dengan kabel berlilit/serabut (Stranded).Kabel Serabut/berlilit (stranded) mempunyai diameter bulat dengan ukuran $1 \mathrm{~mm}^{2}-500 \mathrm{~mm}^{2}$. Untuk lebih jelasnya lihat pada gambar dibawah ini

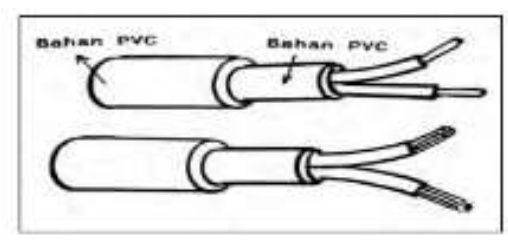

Gambar.2. Kabel serabut/berlilit (stranded) 


\section{Mini Circuit Breaker (MCB)}

MCB merupakan alat pengaman arus lebih pada saluran instalasi listrik yang disebabkan oleh hubung singkat dan beban lebih. MCB bekerja menggunakan 2 jenis Logam yang disebut dengan bimetal yang dapat menarik tuas pada MCB untuk memutuskan tenaga listrik pada instalasi listrik dengan menggunakan elektromagnetik. Dwilogam ini akan bekerja jika ada arus lebih yang menyebabkan terjadi panas yang berlebihan pada dwilogam yang menyebabkan MCB bekerja untuk memutus (Trip) tenaga listrik pada instalasi listrik. Komponen MCB dapat dilihat pada gambar.

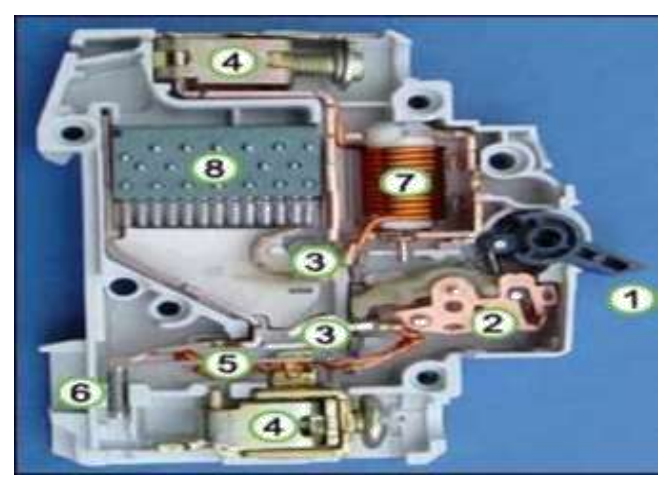

Gambar.3. komponen MCB

Keterangan: 1.Tuas operasi strip, 2.Akuator mekanis, 3.Kontak bergeser, 4.Terminal bawah, 5.Bimetal, 6.Sekrup kalibrasi, 7.Kumparan magnatis, 8.Ruang busur api

MCB menurut fasanya dapat dibedakan menjadi 2 jenis, yaitu jenis satu fasa yang bekerja hanya memiliki satu kutub untuk pengaman 1 fasa, sedangkan jenis 3 fasa biasanya memiliki tiga kutub dengan tuas yang disatukan, sehingga apabila terjadi gangguan pada salah satu kutub maka kutub yang lainnya juga akan ikut terputus.
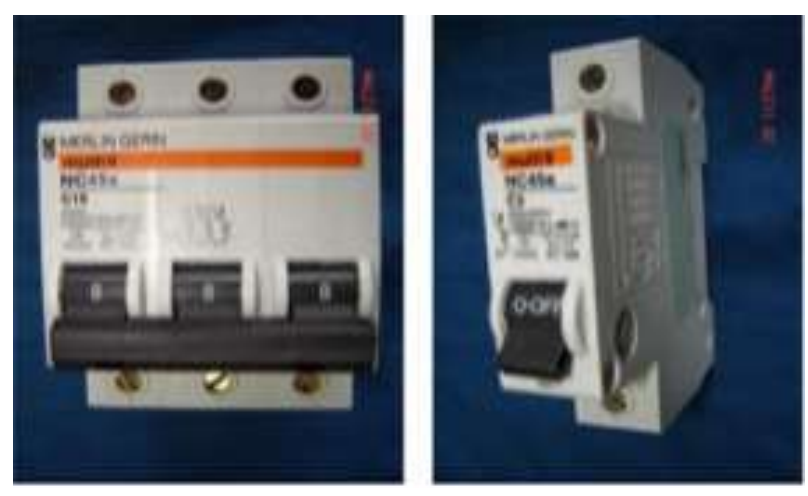

Gambar 4. MCB 3 fasa dan 1 fasa

\section{Pipa Polyvinyl Chloride (PVC).}

Pada pemasangan instalasi listrik banyak sekali dipakai pipa PVC yang digunakan sebagai pelindung kabel atau hantaran dari gangguan terkelupasnya isolasi kabel akibat dimakan tikus dan dengan menggunakan pipa PVC instalasi kelihatan lebih rapi. Pipa PVC yang digunakan biasanya jenis pipa union atau biasa juga pipa PVC dengan ukuran $5 / 8$.

Polyvinyl chloride (PVC) saat ini merupakan bahan yang paling banyak digunakan sebagai bahan isolasi kabel tegangan rendah karena sifatnya yang padat namun dapat dibentuk sesuai dengan kebutuhan dan mempunyai ketahanan terhadap minyak maupun bahan kimia yang lainnya, tetapi tidak dapat didaur ulang. PVC merupakan hasil polimerisasi vinyl chloride $\mathrm{H} 2 \mathrm{C}=\mathrm{CHCl}$. PVC dapat bertahan pada suhu kamar $82 \mathrm{C}^{\circ}$ sampai 105 $\mathrm{C}^{\circ}$. PVC agak lebih mudah menyerap air, sehingga kalau digunakan ditempat lembab atau basah, tahanan isolasinya akan turun.Dapat dilihat di gambar

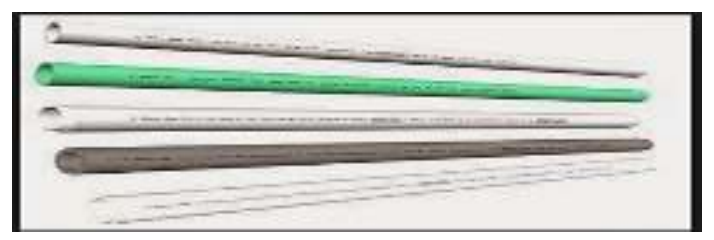

Gambar.5. Pipa PVC

\section{Pengaman (proteksi)}

Pengaman adalah suatu peralatan listrik yang digunakan untuk mengamankan/ melindungi komponen listrik dari kerusakan (tidak Normal) yang diakibatkan oleh gangguan seperti beban lebih, hubung singkat dan tegangan sentuh. Pengaman (proteksi) instalasi listrik dapat berupa kontak otomatis atau Mini Circuit Breaker (MCB) dan Earth Leakege Circuit Breaker (ELCB) dengan pentanahan titik netral (arde).

\section{Tegangan sentuh}

Jika satu kabel yang beraliran listrik terkelupas isolasinya dan tersentuh atau terpegang atau pada stop kontak lubang kabel yang bertegangan tertusuk dengan logam, maka kita akan tersengat aliran listrik yang disebut juga arus bocor. Oleh karena itu dalam pemasangan instalasi listrik 
harus ada pengaman tambahan disamping Miniature Circuit Breaker (MCB). Pengaman tambahan tersebut yaitu Earth Leakege Circuit Breaker (ELCB) dengan pentanahan titik netral (arde).

\section{Earth Leakage Circuit Breaker (ELCB)}

Earth Leakage Circuit Breaker (ELCB) adalah pengaman arus bocor yang disebabkan adanya tegangan sentuh pada saluran instalasi listrik yang mengakibatkan ELCB bekerja dan dapat memutuskan (break) beban dari sumber.

Arus bocor adalah arus yang keluar dari saluran instalasi listrik dan tidak dimanfaatkan (arus hilang). Arus bocor sendiri ada yang langsung mengalir ke bumi melaui arde dan ada juga arus bocor yang mengalir ke tubuh kita yang akhirnya pengaman ELCB akan bekerja off. Komponen utama Pengaman Earth Leakage Circuit Breaker (ELCB), seperti terlihat pada gambar.

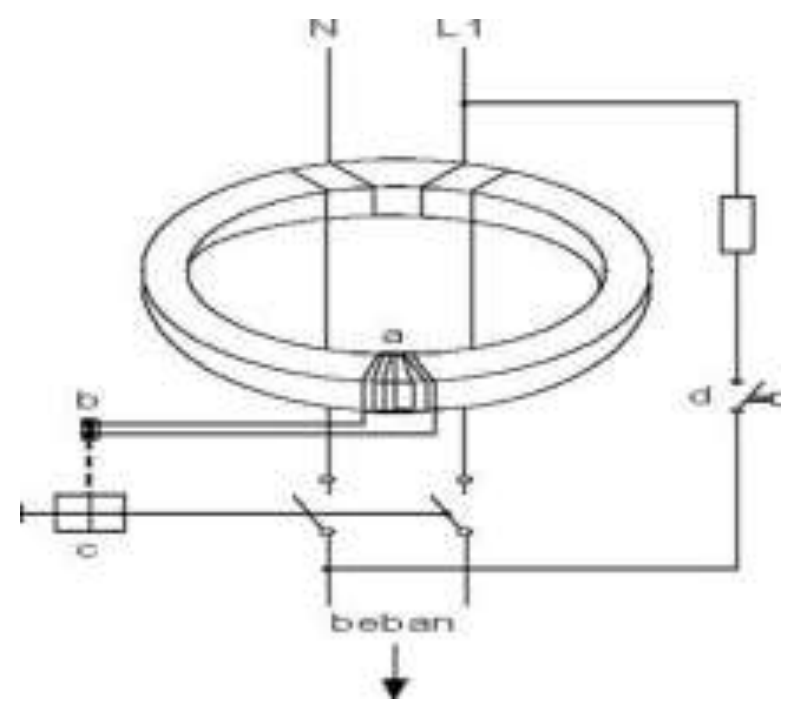

Gambar.6.Komponen ELCB

keterangan: a. Kumparan sekunder

b. Detektor arus gangguan

c. Mekanisme penahan

d. Tombol uji

N. Netral masuk

L1. Fasa masuk

Prinsip kerja ELCB sistem 1 fasa adalah Bila tidak ada arus bocor (ke tanah atau tubuh manusia) maka jumlah arus yang mengalir dalam kedua penghantar $\left(\mathrm{N}\right.$ dan $\left.\mathrm{L}_{1}\right)$ sama dengan nol. Sehingga trafo arus (CT) tidak mengalami induksi listrik dan trigger elektromagnet tidak aktif. Namun sebaliknya bila ada arus bocor, maka jumlah resultante arus yang mengalir pada kedua penghantar $\left(\mathrm{N}\right.$ dan $\left.\mathrm{L}_{1}\right)$ menjadi besar (Lebih), sehingga arusnya tidak sama dengan nol, mengakibatkan CT terinduksi arus lebih dan relay bekerja mengaktifkan trigger, sehingga tuas ELCB ini bekerja dan memutuskan beban dari sumber.

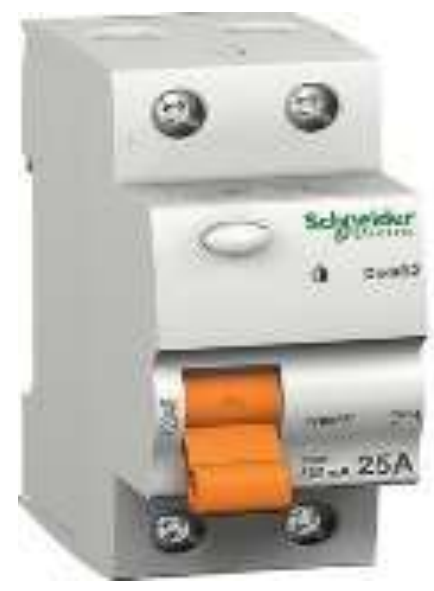

Gambar.7 ELCB 1 fasa

Earth Leakage Circuit Breaker (ELCB) disetting dengan arus bocor nominal $30 \mathrm{~mA}$. Saklar ini cukup aman karena akan bekerja ketika merasakan adanya arus bocor sebesar $30 \mathrm{~mA}$, dan kita tahu bahwa arus bocor yang tersentuh kita dibawah $50 \mathrm{~mA}$ tidak dirasakan oleh tubuh kita karena masih dapat ditahan tanpa menimbulkan gejala-gejala berbahaya. Macam-macam bahaya arus listrik yang mengalir pada tubuh (menyengat tubuh). Terlihat pada grafik 1.

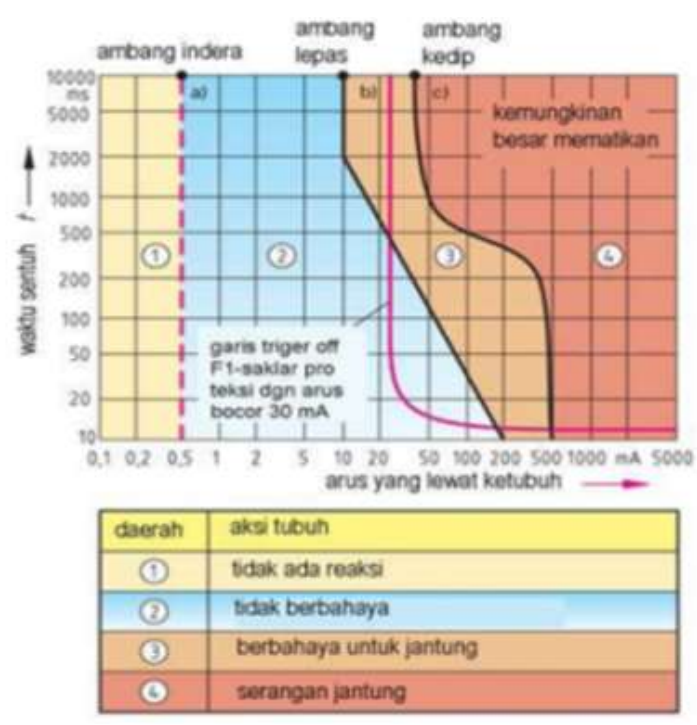

Grafik .1. Bahaya arus listrik dalam grafik 
Besar arus listrik yang mengalir dalam tubuh ditentukan oleh besarnya tegangan yang digunakan dan ketahanan tubuh. Ketahanan tubuh manusia bervariasi tergantung pada jenis, kelembaban kulit dan faktor-faktor lain seperti ukuran tubuh dan berat badan. Tahanan kontak kulit bervariasi dari $1000 \mathrm{k} \Omega$ (kulit kering) sampai $100 \Omega$ (kulit basah). Tahanan dalam (internal) tubuh sendiri antara $100-500 \Omega$ (Hutahuruk, 1991).

\section{Perancangan ELCB dengan instalasi listrik}

Perancangan adalah Pemasangan/ perakitan ELCB dengan beberapa peralatan instalasi Listrik yang disatukan dalam suatu rangkaian (set) dan dapat digunakan untuk keperluan suatu sistem pengaman instalasi listrik yang baik dan benar. Urutan dari perancangan ELCB dengan peralatan instalasi listrik yang digunakan meliputi:

1. Membuat Single Line Diagram.

2. Membuat Single Line Pipa

3. cara pemasangan $\mathrm{PHB}$

4. cara pemasangan ELCB

5. cara pemasangan arde

6. cara menyambungkan kabel di tempat kotak sambung

7. cara pemasangan saklar

8. cara pemasangan stop kontak

9. cara pemasangan fitting lampu

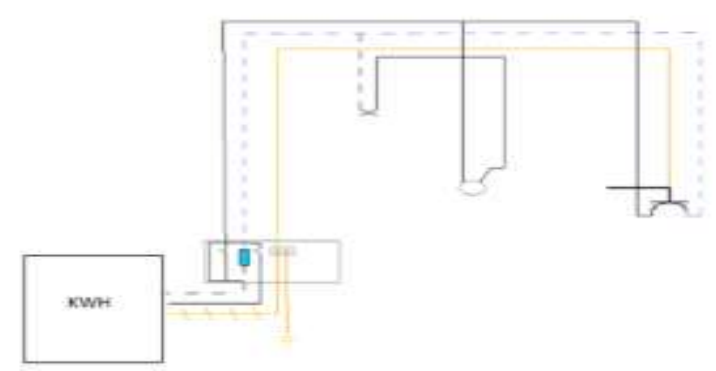

$\mathrm{MCB}$ dan ELCB =

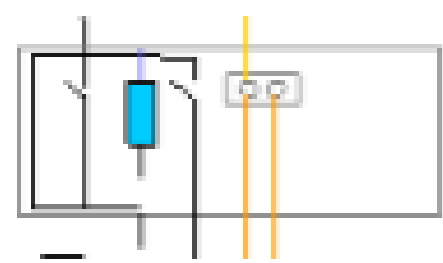

Gambar.8 Lokasi tempat pengaman ELCB

\section{Pemasangan ELCB}

Pastikan kedua kabel netral dan fasa benar benar dihubungkan ke alat pengaman ELCB. jika terdapat satu kabel netral/fasa yang tidak terhubung dengan pengaman ELCB, maka ELCB akan selalu memutuskan rangkaian listrik (trip), karena ELCB mendeteksi hal tersebut bocor. Berikut cara pemasangannya:

1) Masukan kabel fasa dari MCB ke fasa ELCB masuk/IN

2) Masukan kabel fasa dari instalasi ke fasa ELCB keluar/OUT

3) Masukan kabel NYM netral ke netral ELCB masuk/IN

4) Masukan kabel netral instalasi ke netral ELCB keluar/OUT

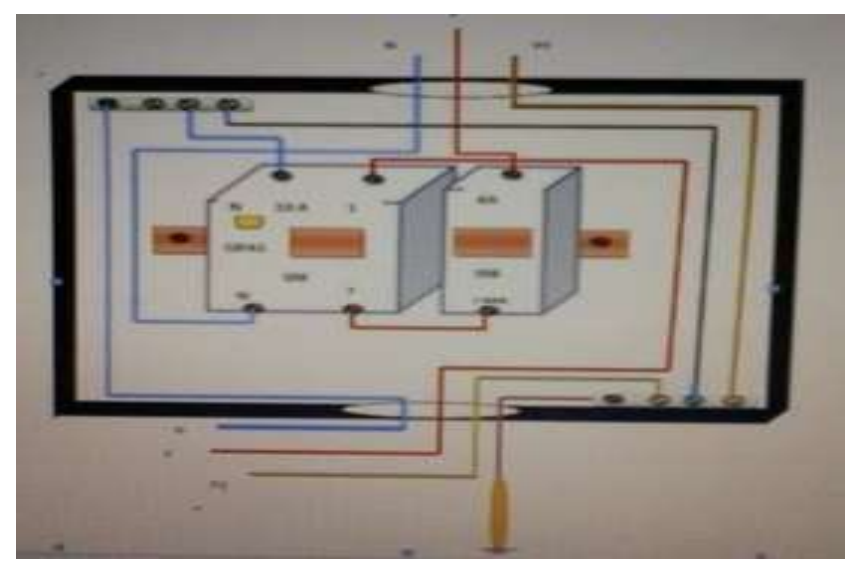

Gambar.9..Pemasangan ELCB

\section{Pentanahan Titik netral/pembumian (Arde)}

Pembumian/Pentanahan titk netral/arde adalah berupa pipa besi atau tembga yang disebut dengan elektroda (konduktor) yang dimasukkan ke dalam tanah (bumi) yang disambung dengan kawat penghantar BC pada bagian ujung atas yang akan dihubungkan dengan suatu peralatan listrik (ELCB).

Grounding rod atau batang tembaga/arde yang ditanam di dalam tanah. terdiri dari pipa galvanis medium $3 / 4$, kawat tembaga BC/NYA, dengan ukuran diameter $16 \mathrm{~mm} 2$, dan dilengkapi dengan splitzen yang dikencangkan dengan baut. panjang grounding rod ini ditanam ditanah biasanya dengan kedalaman antara $1.5 \mathrm{~m} \mathrm{~s} / \mathrm{d} 3 \mathrm{~m}$ (tergantung kondisi tanah), dimana cara pemasangannya sebagai berikut : Masukan batangan elektroda arde ke tanah dan ujung elektroda bagian atasnya di sambungkan dengan terminal kotak penghubung ELCB menggunakan kawat $\mathrm{BC}$, maka pengaman ELCB dengan bumi sudah terhubung. 


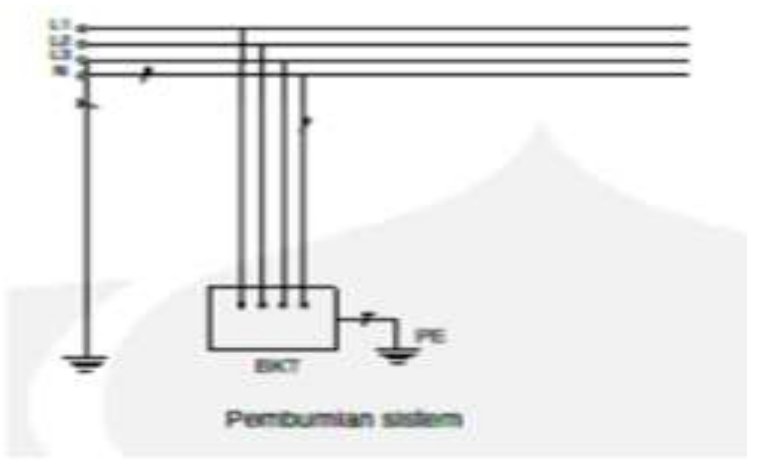

Gambar.10.PentanahanTitikNetral /Arde

\section{Pentanahan Titik Netral/Arde}

Jenis Pentanahan pentanahan Titik Netral/Arde yang juga disebut dengan elektroda bila menurut bentuk dari elektroda yang digunaakan dapat di bedakan menjadi 2 jenis pentanahan titik netral, yaitu Elektroda Batang dan Elektroda Plat

Elektroda batang yaitu elektroda dari pipa besi/ baja profil yang dipancangkan ke dalam tanah. Elektroda ini merupakan elektroda yang pertama kali digunakan dan teori-teori berawal dari elektroda jenis ini. Elektroda ini banyak digunakan pada gardu induk. Secara teknis, elektroda jenis ini mudah pemasangannya dan tidak memerlukan lahan yang luas. Elektroda batang biasanya ditanam dengan kedalaman yang cukup dalam.

Elektroda plat merupakan elektroda dari bahan pelat baja/ logam yang ditempatkan diujung di ujung bagian bawah, dimana lembaran plat baja diletakkan didalam satu lobang besar dibawah tanah/bumi diinginkan tahanan pentanahan yang kecil dan yang sulit diperoleh dengan menggunakan jenis- jenis elektroda yang lain.
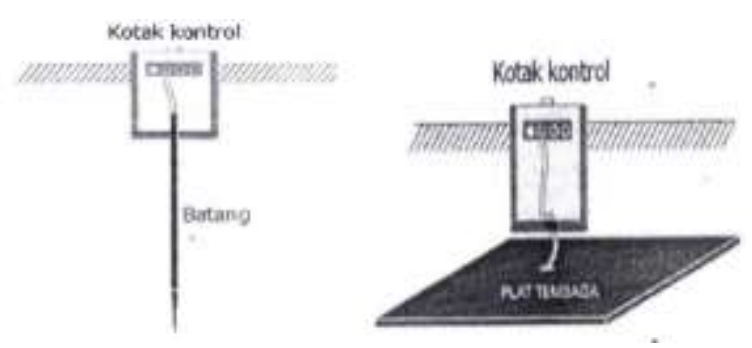

Gambar .11 Elektroda Batang dan Plat

\section{Kedalaman dan kondisi tanah}

Harga tahanan jenis selalu bervariasi sesuai dengan keadaan pada saat pengukuran. Makin tinggi suhu makin tinggi tahanan jenisnya. Sebaliknya makin lembab tanah itu makin rendah tahanan jenisnya. Secara umum harga-harga tahanan jenis ini diperlihatkan pada tabel berikut ini :

Tabel .2. Kedalaman dan kondisi tanah

\begin{tabular}{|c|c|c|c|c|c|c|c|}
\hline \multirow{3}{*}{ Jenis Tanah } & \multirow{3}{*}{$\begin{array}{c}\text { Tahanan } \\
\text { Jenis } \\
\text { Tanah } \\
R_{E} \\
\text { MO }\end{array}$} & \multicolumn{6}{|c|}{ Tahanan Pentanahan } \\
\hline & & \multicolumn{3}{|c|}{$\begin{array}{c}\text { Kedalaman Electroda } \\
\text { ke tanah } \\
\text { (Meter) }\end{array}$} & \multicolumn{3}{|c|}{$\begin{array}{l}\text { Potongan } \\
\text { Pentanahan } \\
\text { (Meter) }\end{array}$} \\
\hline & & 3 & 6 & 10 & 5 & 10 & 20 \\
\hline $\begin{array}{l}\text { Tanah lembab, seperti } \\
\text { rawa }\end{array}$ & 30 & 10 & 5 & 3 & 12 & 6 & 3 \\
\hline $\begin{array}{l}\text { Tanah Pertanian, } \\
\text { tanah liat }\end{array}$ & 100 & 33 & 17 & 10 & 40 & 20 & 10 \\
\hline Tanah liat berpasir & 150 & 50 & 25 & 15 & 60 & 30 & 15 \\
\hline $\begin{array}{l}\text { Tanah lembab } \\
\text { berpasir }\end{array}$ & 300 & 66 & 33 & 20 & 80 & 40 & 20 \\
\hline Campuran 1.5 & 400 & - & - & - & 160 & 80 & 40 \\
\hline Kerikil lembab & 500 & 160 & 80 & 48 & 200 & 100 & 50 \\
\hline Tanah kering berpasir & 1000 & 330 & 165 & 100 & 400 & 200 & 100 \\
\hline Kerikil kering & 1000 & 330 & 165 & 100 & 400 & 200 & 100 \\
\hline Tanah berbatu & 30.000 & 1000 & 500 & 300 & 1200 & 600 & 300 \\
\hline Batu karang & $10^{7}$ & - & - & - & - & - & - \\
\hline
\end{tabular}

\section{KESIMPULAN}

Dari hasil pembahasan Penelitian ini, maka dapat diambil suatu kesimpulan sebagai berikut:

1. Pemasangan instalasi penerangan harus mengunakan peralatan yang sesuai PUIL dan SNI.

2. Penggunakan proteksi ELCB pada Instalasi Listrik masih belum banyak digunakan

3. Jika Instalasi Listrik menggunakan menggunakan proteksi ELCB, Maka instalasi listriknya harus memakai Arde (Pembumian), minimal kedalamannya 3 meter.

4. ELCB adalah alat pengaman arus listrik Bocor yang disebabkan saluran bertegangan Listrik Positif ( + ) tersentuh oleh manusia.

5. Menggunakan pengaman ELCB dengan memasang pentanahan titik netral/arde, wajib dilakukan, karena jika terjadi tegangan sentuh, maka konsumen tidak tersengat listrik dan ELCB dan MCB akan off (Break) dan aliran listrik akan padam.

6. Apabila ELCB tidak dihubungkan dengan Pentanahan titk netral (arde), jika terjadi tegangan sentuh, maka ELCB tidak off (break), Namun konsumen tidak tersengat listrik

\section{DAFTAR PUSTAKA}

Harten, P. van. 1978, Instalasi Listrik Arus Kuat 3, CV.Trimitra Mandiri, Jakarta, 
Nugroho, Rohmat, 2009, Studi Arus Bocor dengan metode pengkuran Inclined Plane Tracking (IPT) pada material polimer High Density Polyethylene (HDPE), Universitas Diponegoro,

Nuril Fifana, 2008, "Modul Simulasi ELCB Satu Fasa Sebagai Pelindung tegangan Sentuh Bagi Manusia”, Universitas Diponegoro.

Sarunggalo Pandung, 2008, Perancangan Earth Leakage Circuit Breaker dengan Sensitivitas 30 mA, Universitas Negeri Papua.

Badan Standarisasi Nasional, 2012, Proteksi terhadap kejut listrik Aspek umum untuk instalasi dan perlengkapan. Diakses dari http://architectdeni.blogspot.com/2013/07/pen gertian-instalasi listrik html.14: 03 ,25 Juli 2017

Tim penyusun PLN dan ESDM, 2000, Peraturan Umum Instalasi Listrik, Bandung. 